\title{
$\mathrm{Li}^{+}$Conduction in Li-Nb-O Films Deposited
}

\section{by a Sol-Gel Method}

\author{
H. Niinomi ${ }^{1,2}$, M. Motoyama ${ }^{1,2}$, and Y. Iriyama ${ }^{1,2}$ \\ ${ }^{1}$ Department of Materials, Physics and Energy Engineering, Nagoya \\ University, Furo-cho, Chikusa-ku, Nagoya, Aichi, 464-8603 Japan \\ ${ }^{2} J S T$-ALCA, 7, Gobancho, Chiyoda-ku, Tokyo, 102-0076 Japan
}

Corresponding author: Prof. Yasutoshi Iriyama, iriyama@ numse.nagoya-

u.ac.jp

Keywords: $\mathrm{Li}$ ion, $\mathrm{LiNbO}_{3}$, amorphous, sol-gel method

\begin{abstract}
We fabricated amorphous Li-Nb-O films by a sol-gel method. The $\mathrm{Li}^{+}$conductivities of Li-Nb-O films were analyzed by ac impedance spectroscopy after annealing at 300 to 450 ${ }^{\circ} \mathrm{C}$. The highest $\mathrm{Li}^{+}$conductivity and lowest activation energy were measured in $\mathrm{Li}-\mathrm{Nb}$ O films annealed at $400{ }^{\circ} \mathrm{C}$. Films annealed at $450{ }^{\circ} \mathrm{C}$ were crystalized to form the non$\mathrm{Li}^{+}$-conductive trigonal $\mathrm{LiNbO}_{3}$ structure. Raman spectroscopy measurements revealed that $\mathrm{Li}-\mathrm{Nb}-\mathrm{O}$ films annealed at $400{ }^{\circ} \mathrm{C}$ had aligned $\mathrm{NbO}_{6}$ octahedra in the structures,
\end{abstract}


although $\mathrm{LiNbO}_{3}$ crystals were undetectable by X-ray diffraction. Additionally, it was found that Li-Nb-O films were preferentially crystalized near the Pt electrode surfaces rather than the quartz surfaces. Hence, Pt nanoparticles (NPs) were pre-deposited on quartz substrates by pulsed laser deposition (PLD) before spin-coating of Li-Nb-O films to investigate the effect of small $\mathrm{LiNbO}_{3}$ crystals on the $\mathrm{Li}^{+}$conductivity. After annealing, the Li-Nb-O films fabricated on Pt-decorated quartz substrates exhibited higher $\mathrm{Li}^{+}$conductivity and lower activation energy in the in-plane direction compared to films on quartz substrates. Thus, it was considered that the amorphous/ $\mathrm{LiNbO}_{3}$ crystal interfaces played an important role in fast $\mathrm{Li}^{+}$conduction. Although the mechanism of $\mathrm{Li}^{+}$conduction in the amorphous/crystal interfacial regions was not well understood, we suggest that reduced attraction between $\mathrm{Li}^{+}$and the terminal oxygen of $\mathrm{NbO}_{6}$ octahedra in the amorphous/crystal interfacial regions contributed to fast $\mathrm{Li}^{+}$conduction.

\section{Introduction}

Many researchers have devoted significant effort into the development of high performance solid-state $\mathrm{Li}^{+}$conductors because all-solid-state-lithium batteries (SSLB) have been considered one of the leading candidates to achieve energy densities higher than those of lithium ion batteries with organic liquid electrolytes [1,2].

Inorganic solid $\mathrm{Li}^{+}$electrolytes for SSLB are mainly categorized into sulfide-based electrolytes [3] and oxide-based electrolytes [4-6] because lithium nitride and lithium halides have poor oxidative stability. $\mathrm{LiBH}_{4}$ has good electrochemical stability and ionic conductivity, but it is a flammable material. 
Sulfide-based electrolytes generally have higher $\mathrm{Li}^{+}$conductivities than oxide-based electrolytes, though the chemical instability of sulfide compounds in air is a significant challenge to overcome for use in practical applications. In comparison to organic liquid electrolytes, oxide-based electrolytes are stable in air and are non-flammable.

However, a critical problem for oxide-based SSLB is that usually there is a large resistance at the solid electrode/solid electrolyte interface and at grain boundaries because point contacts form at these interfaces. Electrode active materials such as $\mathrm{LiCoO}_{2}$ have anisotropic $\mathrm{Li}^{+}$diffusivities depending on crystal orientation. Crystalline $\mathrm{Li}^{+}$electrolytes have anisotropic $\mathrm{Li}^{+}$conductivities as well. It is almost impossible to align the crystal axes for both materials in which $\mathrm{Li}^{+}$can move the fastest at all the interfaces in SSLB. To address this interfacial issue, an ideal interfacial structure could be a thin amorphous electrolyte filling the gap between the electrode active material and the crystalline electrolyte to decrease high interfacial and grain boundary resistances of oxide-based electrolytes. Since $\mathrm{Li}^{+}$conduction is isotropic in an amorphous film, the amorphous interlayer provides facile transport of $\mathrm{Li}^{+}$between the crystalline electrolyte and the electrode active material. However, amorphous $\mathrm{Li}^{+}$electrolytes such as LiPON [7] have lower ionic conductivity compared to crystalline $\mathrm{Li}^{+}$electrolytes such as $\mathrm{Li}_{7} \mathrm{La}_{3} \mathrm{Zr}_{2} \mathrm{O}_{12}$ (LLZ) [5]. As such, amorphous interlayers need to be as thin as possible. A thin film deposition technique for preparing amorphous $\mathrm{Li}^{+}$electrolytes thus plays an important role.

Oxide-based amorphous electrolytes usually have $\mathrm{Li}^{+}$conductivities on the order of $10^{-8}$ to $10^{-6} \mathrm{~S} \mathrm{~cm}^{-1}$ with activation energies from approximately 50 to $60 \mathrm{~kJ} \mathrm{~mol}^{-1}$ [7-12]. Among these, Glass et al. reported that $\mathrm{Li}_{2} \mathrm{O}-\mathrm{Nb}_{2} \mathrm{O}_{5}$ glass with an approximate molar 
ratio of 1:1 had a high $\mathrm{Li}^{+}$conductivity on the order of $10^{-6} \mathrm{~S} \mathrm{~cm}^{-1}$ [13]. They produced $\mathrm{Li}_{2} \mathrm{O}-\mathrm{Nb}_{2} \mathrm{O}_{5}$ glass by a roller quenching method. Since their report, no researchers have successfully produced $\mathrm{Li}-\mathrm{Nb}-\mathrm{O}$ glass with $\mathrm{Li}^{+}$conductivity on the same order of magnitude. For instance, Özer and Lampert fabricated amorphous Li-Nb-O films by a sol-gel method and reported 6-8 $\times 10^{-7} \mathrm{~S} \mathrm{~cm}^{-1}$ at room temperature [14].

The aim of this study was to synthesize thin films of amorphous $\mathrm{Li}-\mathrm{Nb}-\mathrm{O}$ with high $\mathrm{Li}^{+}$ conductivity by the sol-gel method. We also investigated the reason that Li-Nb-O films annealed slightly below the crystallization temperature had high $\mathrm{Li}^{+}$conductivity.

\section{Experimental}

$0.3 \mathrm{~mol} \mathrm{~L} \mathrm{~L}^{-1}$ lithium ethoxide and $0.3 \mathrm{~mol} \mathrm{~L}^{-1}$ niobium ethoxide solutions were separately prepared by diluting $1.0 \mathrm{~mol} \mathrm{~L}^{-1}$ lithium ethoxide (95\%, Sigma-Aldrich) and $4.0 \mathrm{~mol} \mathrm{~L}^{-1}$ niobium ethoxide (99.95\%, Sigma-Aldrich) with dehydrated ethanol in an $\mathrm{Ar}$ atmosphere. These solutions were mixed in a 1:1 volume ratio. $100 \mu \mathrm{L}$ of the mixed solution was dropped onto quartz substrates with interdigitated Pt electrodes (Fig. 1), and thin films were obtained by a spin-coating technique. The spin rate was maintained at $4000 \mathrm{rpm}$. Subsequently, samples were annealed in a tube furnace in an $\mathrm{O}_{2}$ atmosphere for 1.0 hour. The annealing temperature $\left(T_{\mathrm{a}}\right)$ was set to be higher than $300{ }^{\circ} \mathrm{C}$. The same procedure was repeated to increase the film thicknesses because cracks formed when a film was too thin. Cracking occurred because the film volume decreased after the solvent evaporated. Hence, the first deposited layer was annealed for 2.0 hours in total. The annealing duration will hereinafter be described as the duration for one uninterrupted 
annealing process. The resultant thicknesses were approximately $100 \mathrm{~nm}$, as measured by cross-sectional scanning electron microscope (SEM) observation.

The ionic conductivity of the samples was primarily measured in air with an impedance analyzer (4294A, Agilent Co.) using an amplitude of $20 \mathrm{mV}$ in the frequency range from $40 \mathrm{~Hz}$ to $110 \mathrm{MHz}$. A few samples were measured in an Ar glove box to examine the effect of humidity.

Crystal microstructures of samples were examined by $\mathrm{X}$-ray diffraction $(\mathrm{XRD}, \mathrm{CuK} \alpha$, UltimaIV, Rigaku Co.). Molecular structures of the samples were analyzed by Raman spectroscopy (NRS-5100, Nihon Bunko Co.) with a green laser $(\lambda=532 \mathrm{~nm})$. Raman spectra for $\mathrm{LiNbO}_{3}$ powders (99\%, Sigma-Aldrich) were also measured to compare with our samples.

Pt-nanoparticle (NP) films were deposited by pulsed laser deposition (PLD) with a YAG laser with the forth harmonic $(\lambda=266 \mathrm{~nm}, 480 \mathrm{~mW})$. The PLD was performed for 10 seconds under a chamber pressure of $270 \mathrm{~Pa}$ in an Ar atmosphere. The Pt NPs were imaged by a dynamic-mode atomic force microscope (AFM, S-Image, Hitachi Co.).

\section{Results \& Discussion}

\section{Effect of annealing temperature}

Figure 2 shows XRD patterns of samples annealed at (a) 300, (b) 350, (c) 400, and (d) $450{ }^{\circ} \mathrm{C}$ for 1.0 hour. It was found that samples were amorphous when the annealing temperature, $T_{\mathrm{a}}$, was less than $450{ }^{\circ} \mathrm{C}$. Diffraction peaks suddenly appeared when $T_{\mathrm{a}}$ was 
$450{ }^{\circ} \mathrm{C}$. These peaks can be assigned to the trigonal $\mathrm{LiNbO}_{3}$ crystal structure [International Center for Diffraction Data (ICDD) \#00-020-0631]. Moreover, cracks were found in the sample (d) by SEM observation. These results indicate that the crystallization temperature of $\mathrm{LiNbO}_{3}$ was higher than $400{ }^{\circ} \mathrm{C}$ [15]. It was confirmed that the oxidation and decomposition of organic compounds took place at temperatures higher than $150{ }^{\circ} \mathrm{C}$ by differential scanning calorimetry (DSC) (Fig. S1).

Figure 3 shows Nyquist plots (at $100{ }^{\circ} \mathrm{C}$ ) for samples annealed at (a) 300, (b) 350, (c) 400 , and (d) $450{ }^{\circ} \mathrm{C}$ for 1.0 hour. The semicircular arc in the higher frequency range (> $10^{4} \mathrm{~Hz}$ ) was associated with the $\mathrm{Li}^{+}$conduction in the $\mathrm{Li}-\mathrm{Nb}-\mathrm{O}$ film. The film resistance decreased with increasing $T_{\mathrm{a}}$, but it suddenly increased at $T_{\mathrm{a}}=450{ }^{\circ} \mathrm{C}$ (see the inset) because the $\mathrm{LiNbO}_{3}$ crystal is not a $\mathrm{Li}^{+}$conductor. A slope with an approximately $45^{\circ}$ angle appeared in a narrow frequency range on the order of $10^{3} \mathrm{kHz}$ in (a), (b), and (c). This slope is still under investigation, but it is suspected that a new phase formed after annealing at the interfaces between Pt electrodes and an amorphous Li-Nb-O film, such as thin Li-Pt alloy layer.

Figure 4 shows the Arrhenius plots for the $\mathrm{Li}^{+}$conductivities, $\sigma$, of samples that were evaluated by the arc diameters in Nyquist plots. $\sigma$ was estimated by assuming rectangular $\mathrm{Li}^{+}$conduction paths (height : length : width $=100 \mathrm{~nm}: 3.0 \mu \mathrm{m}: 2.0 \mathrm{~mm}$ ) between 129 couples of Pt electrodes. However, the electric fields between Pt electrodes will be distorted in the vicinity of the Pt electrode edges (Fig. 1). This led to only 3\% underestimation of $\sigma$ based on the two-dimensional (2D) finite difference analysis. Hence, the effect of non-uniform electric fields was negligible. 
All plots followed linear slopes in Fig. 4. The activation energy, $E_{\mathrm{a}}$, for the $\mathrm{Li}^{+}$ conduction decreased with increasing $T_{\mathrm{a}}$ to $400{ }^{\circ} \mathrm{C}$. The $\mathrm{LiNbO}_{3}$-crystallized sample $\left(T_{\mathrm{a}}\right.$ $\left.=450{ }^{\circ} \mathrm{C}\right)$ had the lowest $\sigma[(\mathrm{d})$ in Fig. 4].

Figure 5 (Top) and (Bottom) show $\sigma\left(\right.$ at $25^{\circ} \mathrm{C}$ ) and $E_{\mathrm{a}}$ of $\mathrm{Li}-\mathrm{Nb}-\mathrm{O}$ films as a function of $T_{\mathrm{a}}$, respectively. The largest $\sigma$ and the smallest $E_{\mathrm{a}}$ were measured at $T_{\mathrm{a}}=400{ }^{\circ} \mathrm{C}$. However, the $\sigma$ and $E_{\mathrm{a}}$ values were significantly different depending on the sample at $T_{\mathrm{a}}$ $=400{ }^{\circ} \mathrm{C}$ (three or four samples were measured for each $T_{\mathrm{a}}$ ). The $\mathrm{Li}_{2} \mathrm{O}-\mathrm{Nb}_{2} \mathrm{O}_{5}$ glass electrolyte produced by Glass et al. using a roller quenching method exhibited $\sigma$ of $5 \times$ $10^{-6} \mathrm{~S} \mathrm{~cm}^{-1}$ at $25^{\circ} \mathrm{C}$ and $E_{\mathrm{a}}$ of $38.3 \mathrm{~kJ} \mathrm{~mol}^{-1}$ [13]. Some of our samples at $T_{\mathrm{a}}=400{ }^{\circ} \mathrm{C}$ had $\sigma$ and $E_{\mathrm{a}}$ values similar to the conductivity and activation energy by Glass et al. The $\sigma$ of these samples were also measured in an Ar-filled glove box, but the results were still the same. At $T_{\mathrm{a}}=450{ }^{\circ} \mathrm{C}$, the $\sigma$ significantly decreased due to the $\mathrm{LiNbO}_{3}$ crystallization.

Figure 6 shows the Raman spectra of the samples $\left(T_{\mathrm{a}}=300,350,400,450{ }^{\circ} \mathrm{C}\right.$ for 1.0 hour) and commercial $\mathrm{LiNbO}_{3}$ powders. As described above, the $\sigma$ was significantly different depending on the individual film. For clarity, the spectra for the samples with lower and higher $\sigma$ at $T_{\mathrm{a}}=400{ }^{\circ} \mathrm{C}$ were denoted as $400{ }^{\circ} \mathrm{C}^{\mathrm{L}}$ and $400{ }^{\circ} \mathrm{C}^{\mathrm{H}}$, respectively, in Fig. 6. The Raman spectra clearly changed when $T_{\mathrm{a}}$ was higher than $350{ }^{\circ} \mathrm{C}$. These spectra changed to be more similar to that of commercial $\mathrm{LiNbO}_{3}$ powders with increasing $T_{\mathrm{a}}$. The peaks at $630 \mathrm{~cm}^{-1}$ and $870 \mathrm{~cm}^{-1}$ indicate stretching modes associated with octahedral $\mathrm{NbO}_{6}$ units $[16,17]$. An increase in the integrated area of the peak at 630 $\mathrm{cm}^{-1}$ relative to the peak at $870 \mathrm{~cm}^{-1}$ meant the initiation of $3 \mathrm{D}$ ordering of octahedral $\mathrm{NbO}_{6}$ units. At $T_{\mathrm{a}}=450{ }^{\circ} \mathrm{C}, \mathrm{LiNbO}_{3}$ diffraction peaks appeared in XRD measurements (Fig. 2). 
The Raman spectra of the samples annealed at $400{ }^{\circ} \mathrm{C}$ were different depending on the $\sigma\left(400{ }^{\circ} \mathrm{C}^{\mathrm{L}}\right.$ and $400{ }^{\circ} \mathrm{C}^{\mathrm{H}}$ in Fig. 6). The sample with higher $\sigma\left(400{ }^{\circ} \mathrm{C}^{\mathrm{H}}\right)$ exhibited a spectrum more similar to that of $\mathrm{LiNbO}_{3}$. It is considered that the terminal oxygen of $\mathrm{NbO}_{6}$ octahedra plays a critical role in fast $\mathrm{Li}^{+}$conduction because neighboring $\mathrm{NbO}_{6}$ octahedra share the corners that connect to each other with the terminal oxygen at neighboring positions (inset in Fig. 6) $[\mathbf{1 8}] . \mathrm{Li}^{+}$could hop to sites adjacent to the terminal oxygens to conduct unless $\mathrm{Li}^{+}$is strongly attracted by the negative charges of the terminal oxygen. Electrically unbalanced space charge layers are developed in the interfacial regions between two different solid phases (e.g. amorphous and crystal). It is conceivable that the attraction of $\mathrm{Li}^{+}$to the terminal oxygen can be relaxed by electric fields in these space charge layers.

The nuclear magnetic resonance (NMR) measurements by Heitjans et al. revealed that $\mathrm{Li}^{+}$had higher mobility in the amorphous/crystal interfacial regions compared to the bulk in $\mathrm{LiNbO}_{3}[\mathbf{1 9 , 2 0}]$. It is therefore possible that a large number of small $\mathrm{LiNbO}_{3}$ crystals nucleated at $400{ }^{\circ} \mathrm{C}$ slightly below the crystallization temperature. The interfacial regions with high $\mathrm{Li}^{+}$mobility should be developed in the peripheries of the $\mathrm{LiNbO}_{3}$ crystals in the amorphous $\mathrm{Li}-\mathrm{Nb}-\mathrm{O}$ matrix, as in glass-ceramic electrolytes. $\mathrm{Li}^{+}$ conducted through these interfacial regions around the $\mathrm{LiNbO}_{3}$ crystals. Hence, samples prepared just below the onset temperature of rapid $\mathrm{LiNbO}_{3}$ crystallization were the most conductive. The reason that the measured $\sigma$ values were significantly different depending on individual film at $T_{\mathrm{a}}=400{ }^{\circ} \mathrm{C}$ in Fig. 5 is probably because the nucleation condition was sensitive to unexpected contaminants or dust. It is suspected that a sample with a high $\sigma$ at $T_{\mathrm{a}}=400{ }^{\circ} \mathrm{C}$ contained small $\mathrm{LiNbO}_{3}$ crystals with a large number density. 
Effect of Pt NPs

XRD patterns of samples annealed at $425{ }^{\circ} \mathrm{C}$ for 2.0 hours on Pt and quartz substrates are shown in Fig. 7. Much stronger diffraction peaks of $\mathrm{LiNbO}_{3}$ appeared on Pt than on quartz. It is thus suggested that Pt NPs acted as catalysts to trigger the nucleation of $\mathrm{LiNbO}_{3}$ in a sample. The mechanism of $\mathrm{LiNbO}_{3}$ crystallization on Pt surfaces has yet to be understood. The roles of the platinum oxide layer formation and interdiffusion between $\mathrm{Pt}$ and $\mathrm{Li}-\mathrm{Nb}-\mathrm{O}$ seem to be important. These need to be examined in the future. Nevertheless, it is obvious that Pt surfaces accelerated $\mathrm{LiNbO}_{3}$ crystallization in Fig. 7. As such, Pt-NP films were deposited on quartz substrates with interdigitated Pt electrodes by PLD to introduce the preferential nucleation sites. The PLD duration was 10 seconds, which was too brief for Pt crystals to electrically short the interdigitated electrodes.

Figure 8 shows AFM images of Si wafers before and after depositing Pt NPs by PLD. Albeit with vibrational noises in AFM imaging for (a), small bumps indicating Pt NPs can be recognized after PLD in (b). It is observed that rather than forming contiguous Pt films, the short-duration PLD produced Pt "islands" with diameters less than $10 \mathrm{~nm}$. The distributed Pt islands had separation distances less than $20 \mathrm{~nm}$ between the nearest neighbors.

Figure 9 shows $\sigma\left(\right.$ at $200{ }^{\circ} \mathrm{C}$ ) and $E_{\mathrm{a}}$ of samples on quartz substrates with interdigitated Pt electrodes with and without Pt NPs as a function of annealing duration at $T_{\mathrm{a}}=425^{\circ} \mathrm{C}$. Without Pt NPs, the $\sigma$ decreased after 60 minutes of annealing, as shown in (a). The $E_{\text {a }}$ increased simultaneously. In contrast, the $\sigma$ with Pt NPs slightly increased until 60 
minutes of annealing, as shown in (b). The $E_{\mathrm{a}}$ kept decreasing as the annealing proceeded. It is suspected that numerous small $\mathrm{LiNbO}_{3}$ crystals nucleated on the Pt-NP surfaces, whence a large number of amorphous/crystal interfaces existed in the bottom region of the film as illustrated in the inset of Fig. 9(Top). This situation provided highly- $\mathrm{Li}^{+}$-conductive regions in a $\mathrm{Li}-\mathrm{Nb}-\mathrm{O}$ film and was presumably similar to what occurred in a sample with relatively high $\sigma$ annealed at $400{ }^{\circ} \mathrm{C}$ in Fig. 5. The cooling rates for the samples were possibly different so that the number density of $\mathrm{LiNbO}_{3}$ crystals varied depending on the individual film resulting in a large deviation of $\sigma$ at $T_{\mathrm{a}}=$ $400{ }^{\circ} \mathrm{C}$. The reason that the $\sigma$ started to decrease after 60 minutes in Fig. 9 is because $\mathrm{LiNbO}_{3}$ crystals grew to dominate the entire volume of the sample.

In conclusion, it is suggested that $\mathrm{Li}-\mathrm{Nb}-\mathrm{O}$ films can potentially become excellent amorphous $\mathrm{Li}^{+}$conductors if the amorphous/crystal interfaces can be controlled in the entire volume of the films. One effective approach is to introduce small catalytic particles in a film with a high number density to promote the nucleation of $\mathrm{LiNbO}_{3}$ crystals.

\section{Conclusions}

We fabricated amorphous $\mathrm{Li}-\mathrm{Nb}-\mathrm{O}$ films by a sol-gel method and measured $\mathrm{Li}^{+}$ conductivity and activation energy of the samples. A Li-Nb-O film annealed at $400{ }^{\circ} \mathrm{C}$ for 1.0 hour had the highest $\mathrm{Li}^{+}$conductivity and lowest activation energy. We considered that the structures of partially aligned octahedral $\mathrm{NbO}_{6}$ units existing in the vicinity of the amorphous/crystal interfaces critically contribute to fast $\mathrm{Li}^{+}$conduction. 
To verify this hypothesis, Pt NPs were deposited on a substrate before spin-coating of a Li-Nb-O film. A Li-Nb-O film with Pt NPs showed a slight increase in $\mathrm{Li}^{+}$conductivity due to the annealing at $425{ }^{\circ} \mathrm{C}$. In contrast, the $\mathrm{Li}^{+}$conductivity of a sample without $\mathrm{Pt}$ NPs only decreased as the annealing proceeded.

\section{Acknowledgements}

Financial support for this work by JST-ALCA is gratefully acknowledged. We wish to thank T. Kimura and K. Kimura for the AFM measurements and Prof. W. C. West for the helpful discussion.

\section{References}

1. P. H. L. Notten, F. Roozeboom, R. A. H. Niessen, L. Baggetto, Adv. Mater. 19 (2007) 4564-4567. (DOI: 10.1002/adma.200702398)

2. S. Iwasaki, T. Hamanaka, T. Yamakawa, W. C. West, K. Yamamoto, M. Motoyama, T. Hirayama, Y. Iriyama, J. Power Sources 272 (2014) 1086-1090. (DOI: 10.1016/j.jpowsour.2014.09.038)

3. N. Kamaya, K. Homma, Y. Yamakawa, M. Hirayama, R. Kanno, M. Yonemura, T. Kamiyama, Yuki Kato, S. Hama, K. Kawamoto, A. Mitsui, Nat. Mater. 10 (2011) 682-686. (DOI: 10.1038/NMAT3066) 
4. Y. Inaguma, C. Liquan, M. Itoh, T. Nakamura, T. Uchida, H. Ikuta, M. Wakihara, Solid State Commun. 86 (1993) 689-693. (DOI: 10.1016/0038-1098(93)90841-A)

5. R. Murugan, V. Thangadurai, W. Weppner, Angew. Chem. Int. Ed. 46 (2007) 7778-7781. (DOI: 10.1002/anie.200701144)

6. Y. Inda, T. Katoh, M. Baba, J. Power Sources 174 (2007) 741-744. (DOI: 10.1016/j.jpowsour.2007.06.234)

7. J. B. Bates, N. J. Dudney, G. R. Gruzalski, R. A. Zuhr, A. Choudhury, C. F. Luck, J. Power Sources 43-44 (1993) 103-110. (DOI: 10.1016/0378-7753(93)80106-Y)

8. Y. Ito, K. Miyauchi, T. Oi, J. Non-Cryst. Solids 57 (1983) 389-400. (DOI: $10.1016 / 0022-3093(83) 90426-X)$

9. K. Kuwata, N. Iwagami, J. Kawamura, Solid State Ionics 180 (2009) 644-648. (DOI: 10.1016/j.ssi.2008.09.010)

10. B. V. R. Chowdari, K. L. Tan, R. Gopalakrishnan, J. Non-Cryst. Solids 128 (1991) 18-29. (DOI: 10.1016/0022-3093(91)90773-Y)

11. C. E. Kim, H. C. Hwang, M. Y. Yoon, B. H. Choi, H. J. Hwang, J. Non-Cryst. Solids 357 (2011) 2863-2867. (DOI: 10.1016/j.jnoncrysol.2011.03.022)

12. I. Abrahams, E. Hadzifejzovic, Solid State Ionics 134 (2000) 249-257. (DOI: 10.1016/S0167-2738(00)00768-2)

13. A. M. Glass, K. Nassau, T. J. Negran, J. Appl. Phys. 49 (1978) 4808-4811. (DOI: $10.1063 / 1.325509)$ 
14. N. Özer, C. M. Lampert, Sol. Ener. Mat. Sol. Cell. 39 (1995) 367-375. (DOI: $10.1016 / 0927-0248(96) 80002-X)$

15. S. Satapathy, C. Mukherjee, T. Shaktawat, P. K. Gupta, V. G. Sathe, Thin Solid Films 520 (2012) 6510-6514. (DOI: 10.1016/j.tsf.2012.06.072)

16. J.-M. Jehng, I. E. Wachs, Chem. Mater. 3 (1991) 100-107. (DOI: $10.1021 / \mathrm{cm} 00013 \mathrm{a} 025)$

17. Y. Repelin, E. Husson, F. Bennani, C. Proust, J. Phys. Chem. Solids 60 (1999) 819-825. (DOI: 10.1016/S0022-3697(98)00333-3)

18. Q.-H. Gu, C.-L. Hu, J.-H. Zhang, and J.-G. Mao, Dalton Trans. 40 (2011) 2562-2569. (DOI: 10.1039/c0dt01512a)

19. P. Heitjans, M. Wikening, MRS Bull. 34 (2009) 915-922. (DOI: $10.1557 / \mathrm{mrs} 2009.213)$

20. P. Heitjans, M. Masoud, A. Feldhoff, M. Wilkening, Faraday Discuss. 134 (2007) 67-82. (DOI: 10.1039/b602887j) 


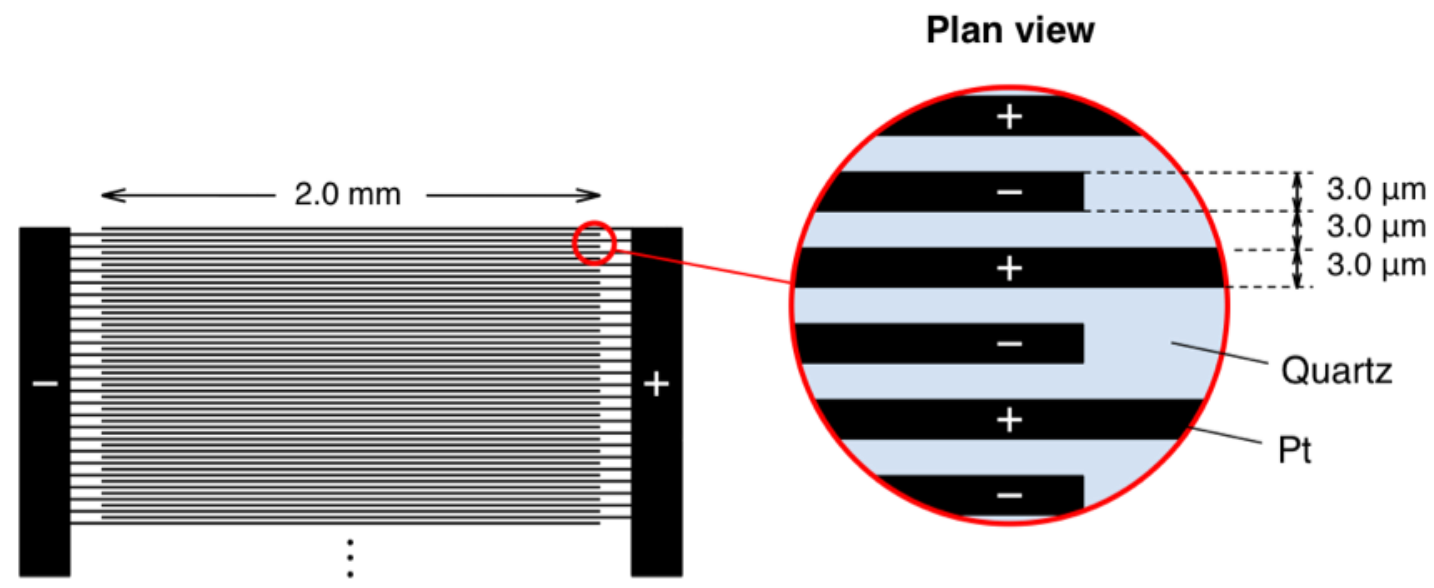

Cross-sectional view

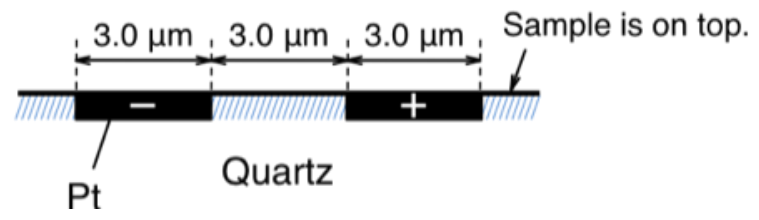

Figure 1. Schematic illustrations of plan and cross-sectional views for interdigitated Pt electrodes embedded in a quartz substrate. There are 65 electrodes for each pole $(+,-)$. The effective lengths and widths of a single rectangular Pt electrode are $2.0 \mathrm{~mm}$ and 3.0 $\mu \mathrm{m}$, respectively. The distance between two Pt electrodes is $3.0 \mu \mathrm{m}$. 


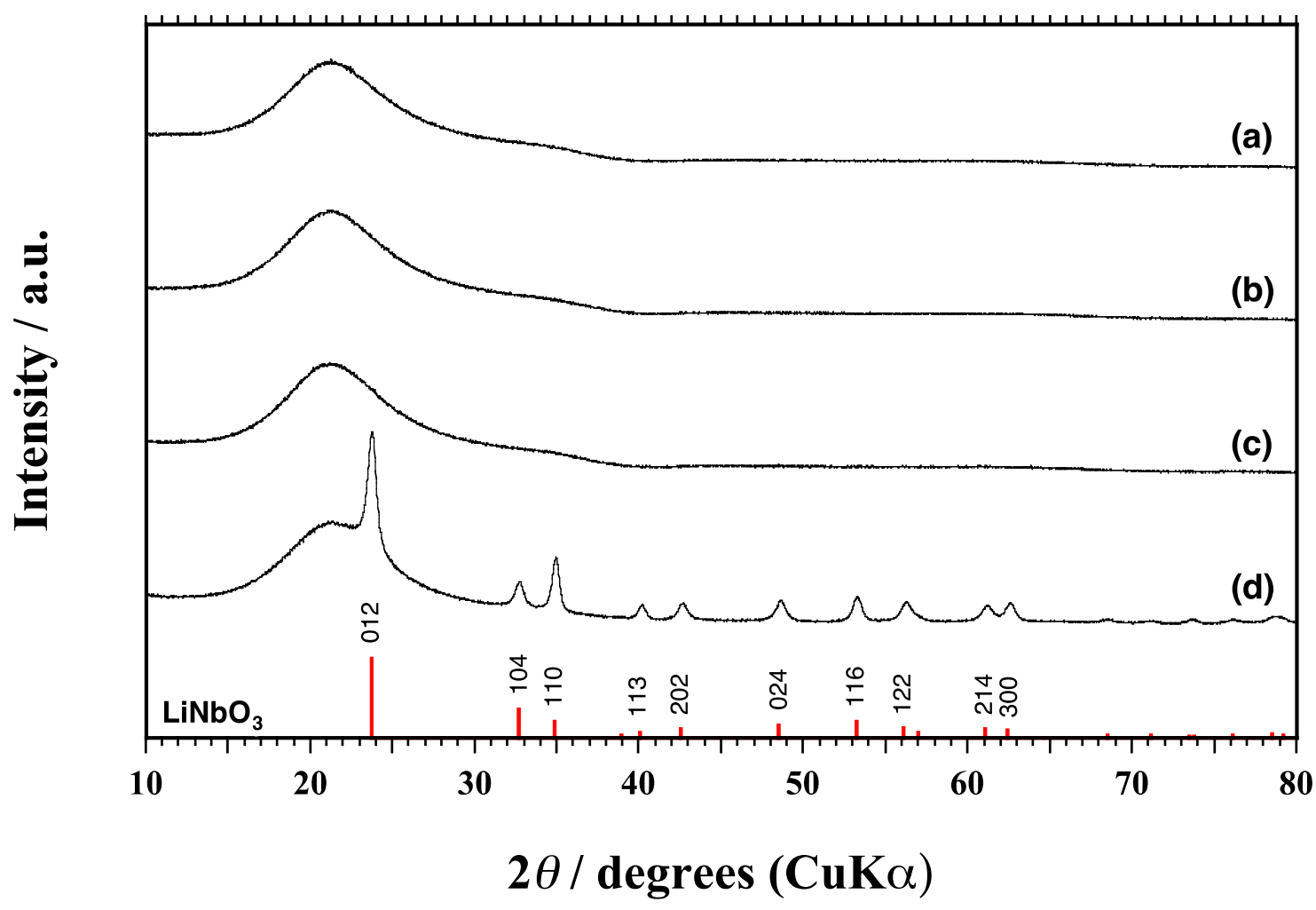

Figure 2. XRD patterns of Li-Nb-O samples after annealing at (a) 300, (b) 350, (c) 400, and (d) $450{ }^{\circ} \mathrm{C}$ for 1.0 hour. The diffraction peak positions for the trigonal $\mathrm{LiNbO}_{3}$ are presented on the bottom. 


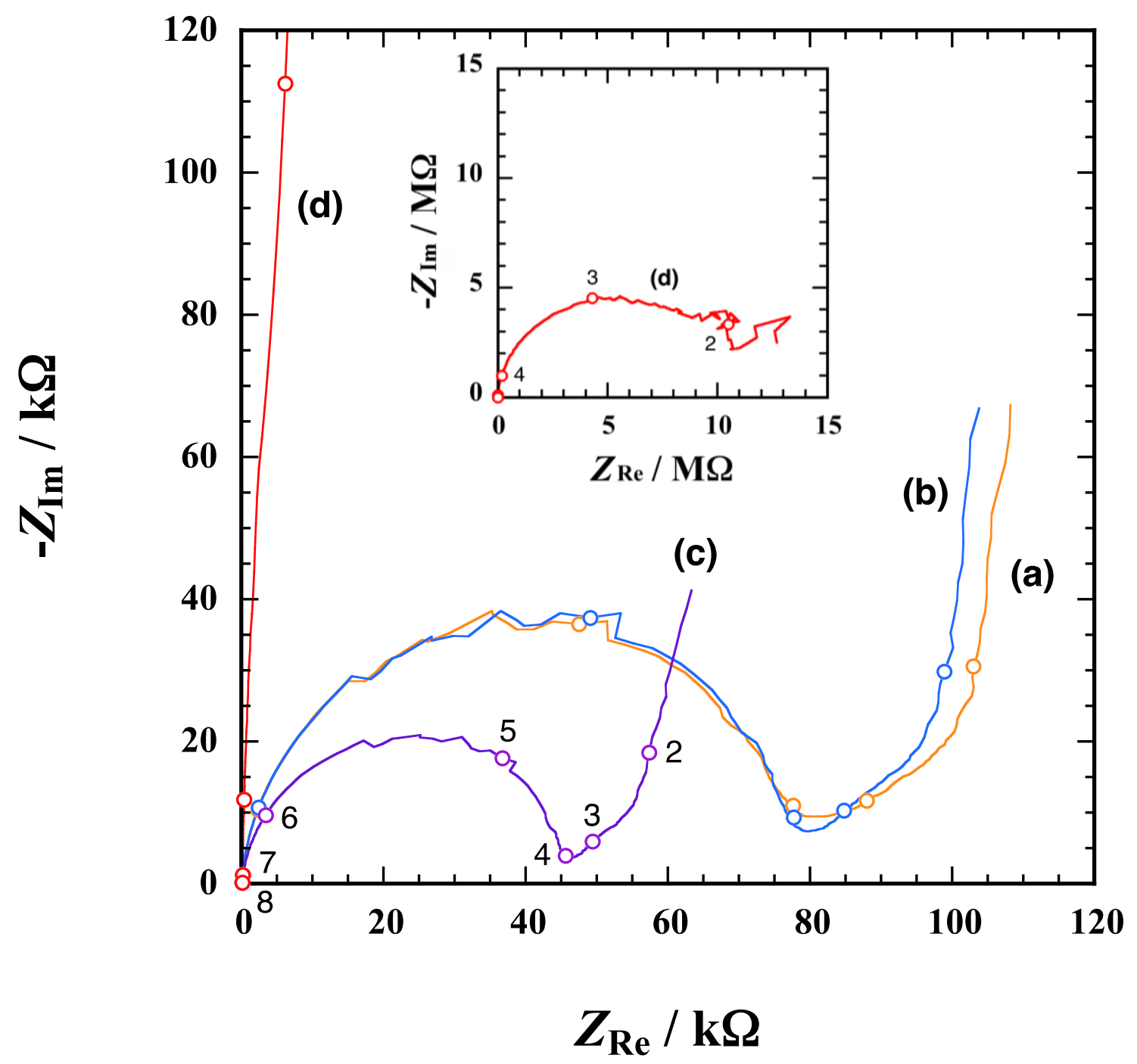

Figure 3. Nyquist plots (at $100{ }^{\circ} \mathrm{C}$ ) for Li-Nb-O films annealed at (a) 300 , (b) 350 , (c) 400, and (d) $450{ }^{\circ} \mathrm{C}$ for 1.0 hour. The inset is for larger impedance values. Frequency: $10^{n} \mathrm{~Hz}$ 


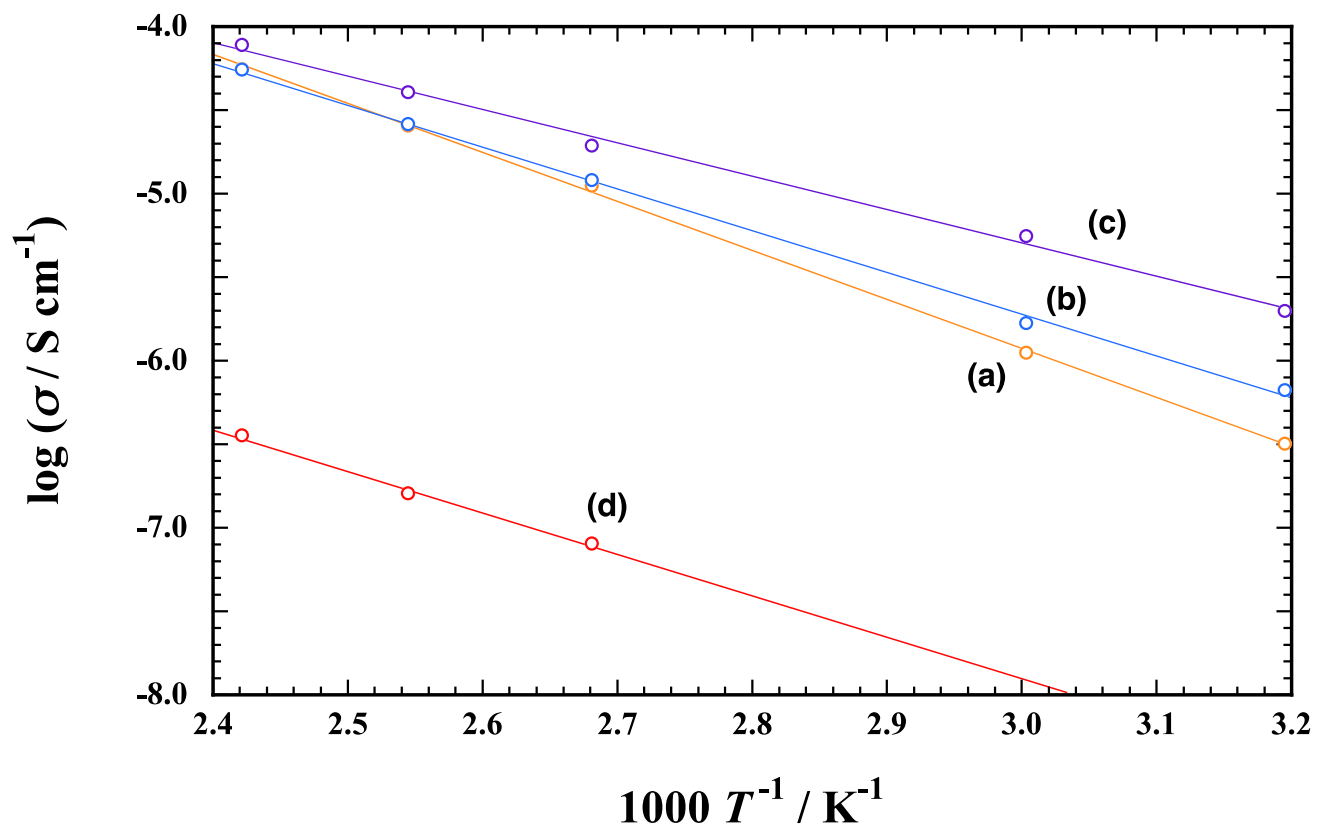

Figure 4. Arrhenius plots for $\mathrm{Li}^{+}$conductivities, $\sigma$, of $\mathrm{Li}-\mathrm{Nb}-\mathrm{O}$ films annealed at (a) 300, (b) 350 , (c) 400 , and (d) $450{ }^{\circ} \mathrm{C}$ for 1.0 hour. 

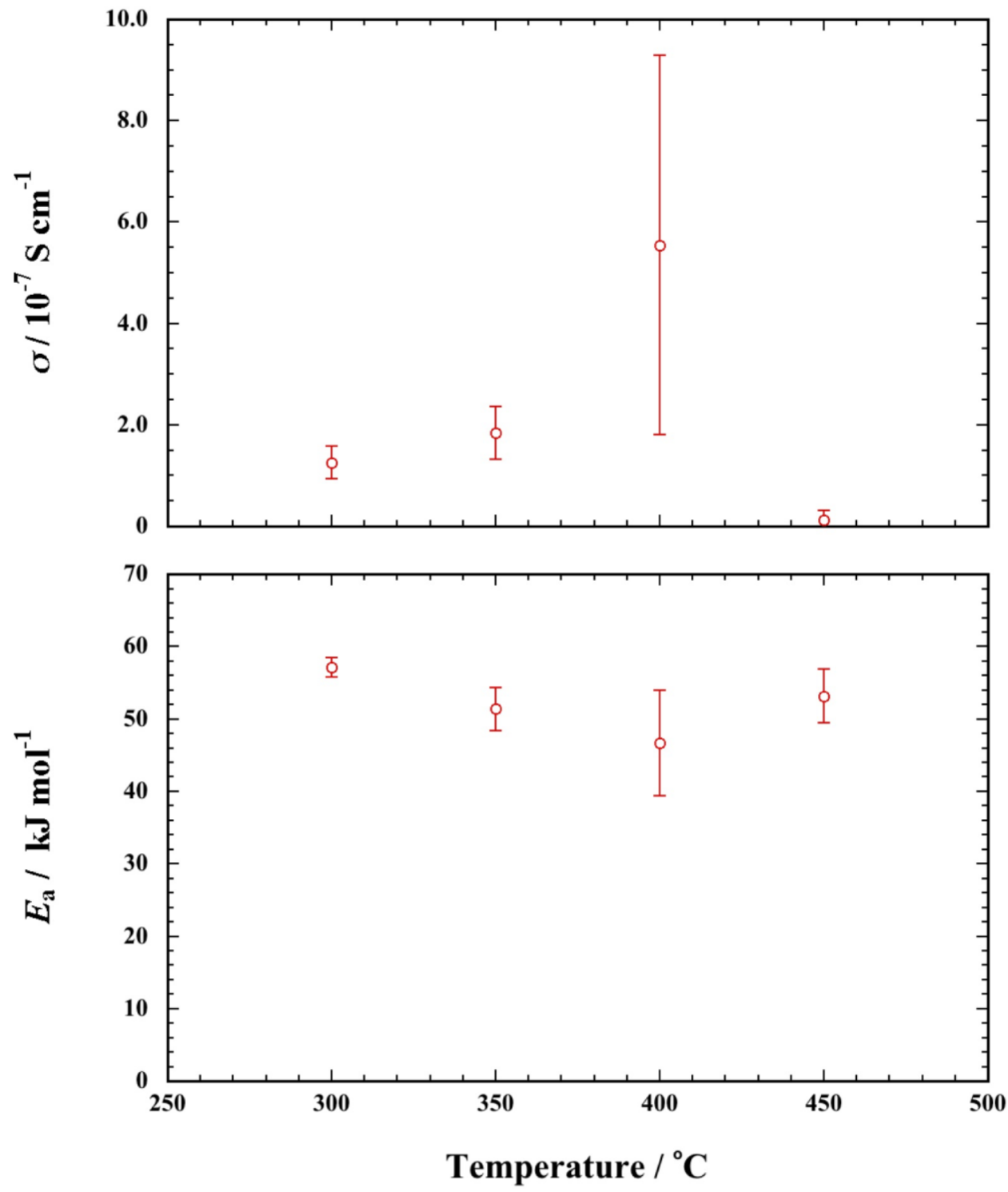

Figure 5. $\sigma$ at $25{ }^{\circ} \mathrm{C}$ (Top) and $E_{\mathrm{a}}$ (Bottom) of samples as a function of annealing temperature. The annealing duration was 1.0 hour. 


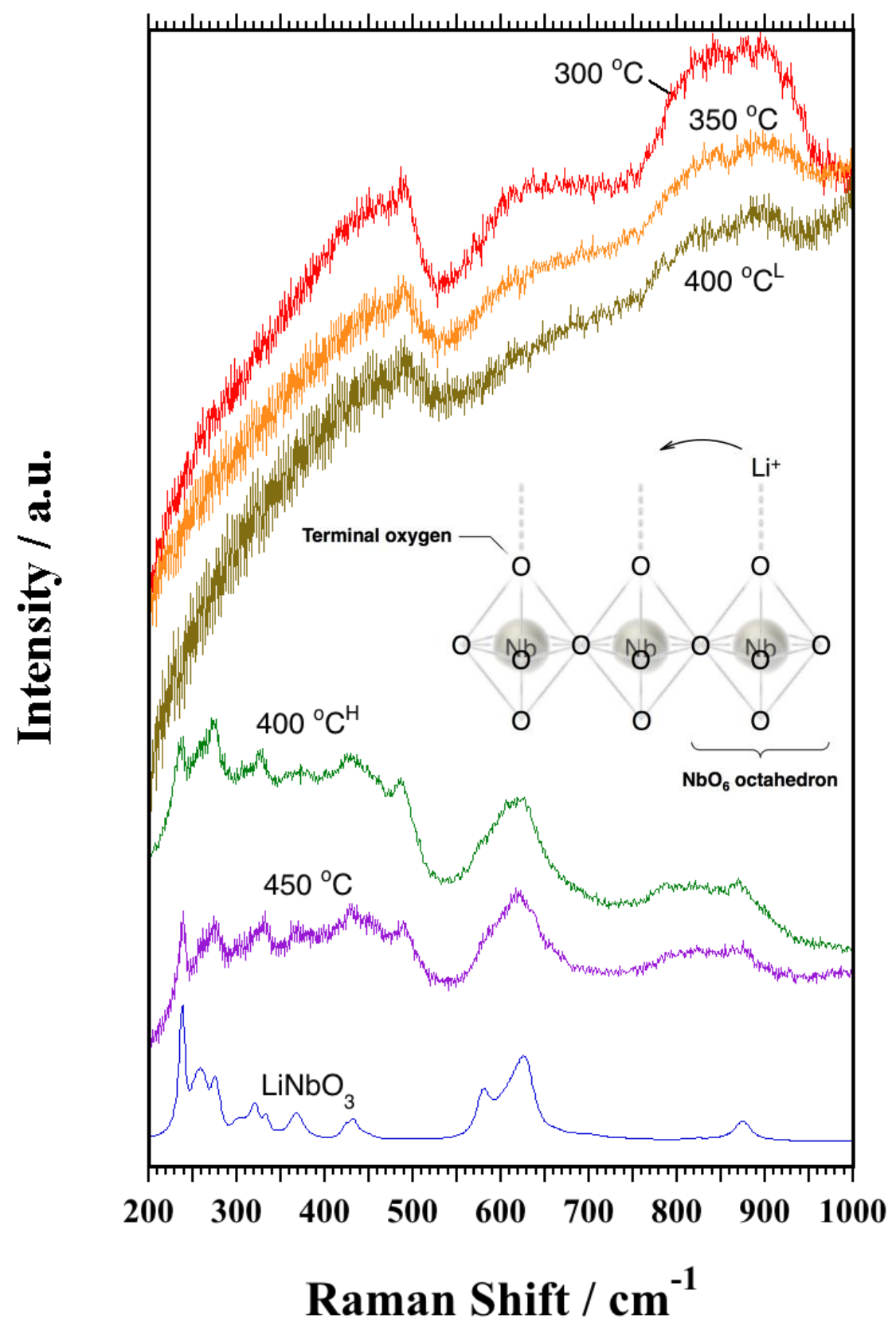

Figure 6. Raman spectra of Li-Nb-O samples with $T_{\mathrm{a}}=300,350,400$, and $450{ }^{\circ} \mathrm{C}$ and commercial crystalline $\mathrm{LiNbO}_{3}$ powders. The annealing duration for the samples was 1.0 hour. The superscripts of $\mathrm{L}$ and $\mathrm{H}$ for $400{ }^{\circ} \mathrm{C}$ denote samples with $E_{\mathrm{a}}=50 \mathrm{~kJ} \mathrm{~mol}^{-1}$ and $38 \mathrm{~kJ} \mathrm{~mol}^{-1}$, respectively (see text). The inset illustrates corner-sharing $\mathrm{NbO}_{6}$ octahedra with $\mathrm{Li}^{+}$hopping on the terminal oxygen. 


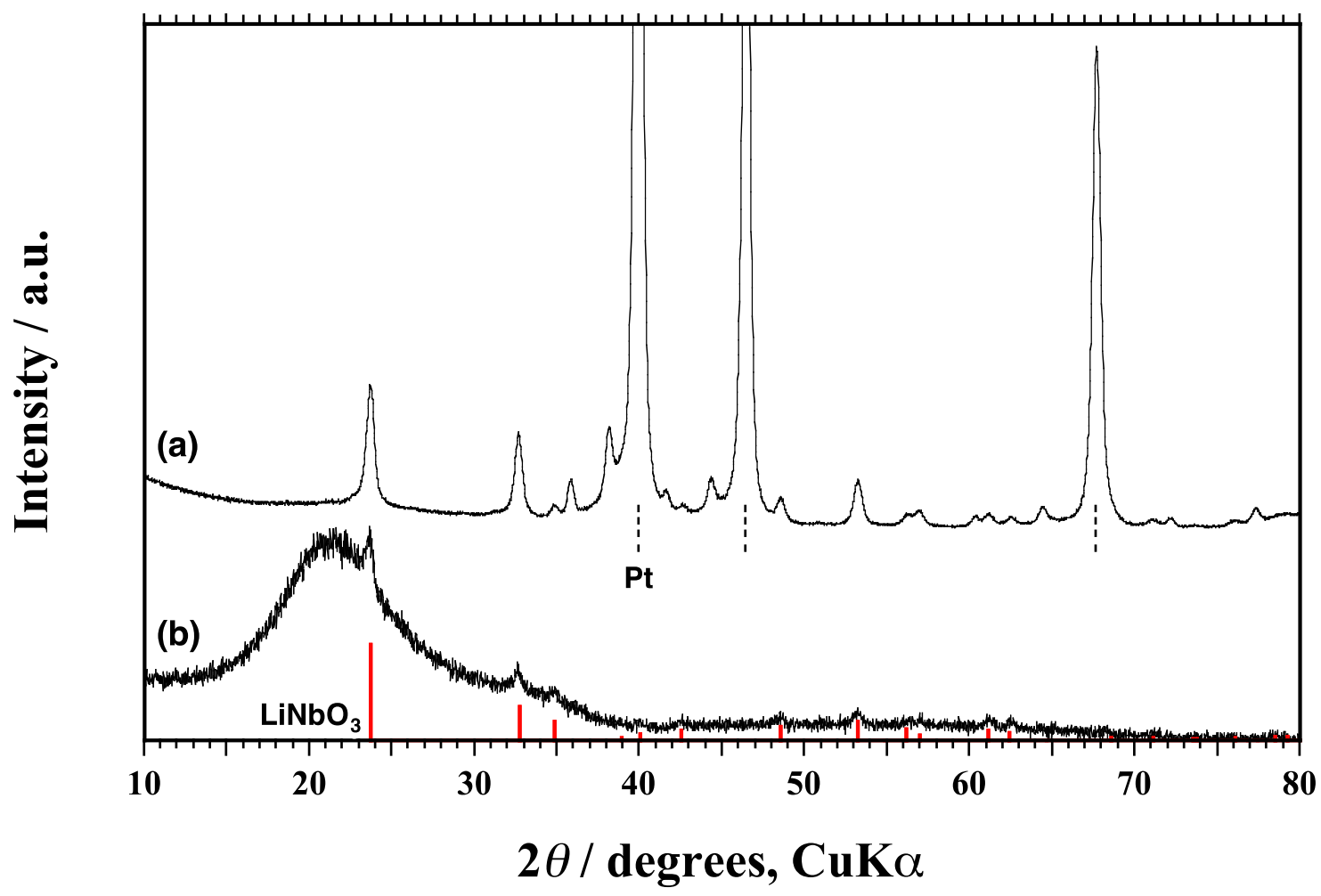

Figure 7. XRD patterns of samples after annealing at $425^{\circ} \mathrm{C}$ for 2.0 hours on (a) $\mathrm{Pt}$ and (b) quartz substrates. The strongest peaks at the dashed lines in (a) indicate Pt diffraction peaks. 
(a)

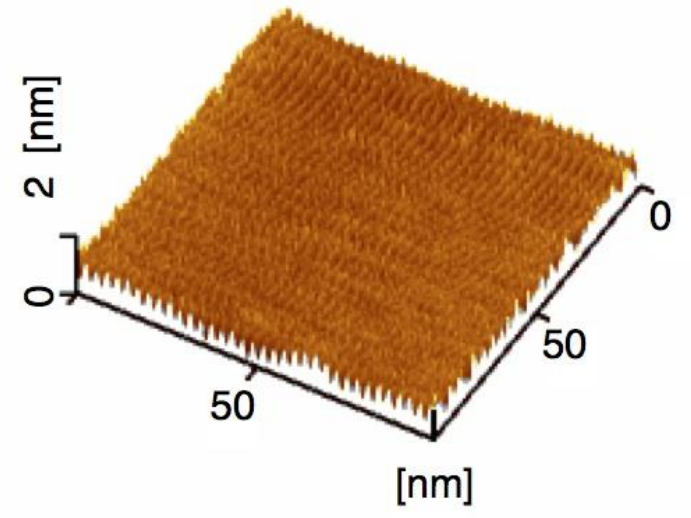

(b)

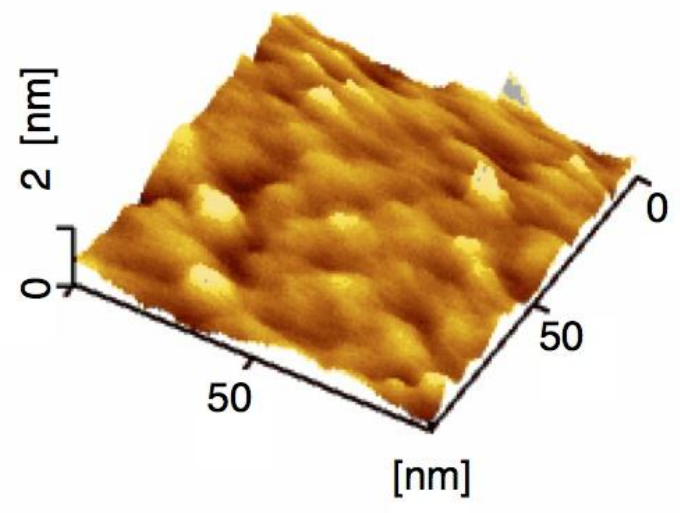

Figure 8. AFM images of $\mathrm{Si}$ wafer surfaces (a) without and (b) with Pt NPs deposited by PLD. 

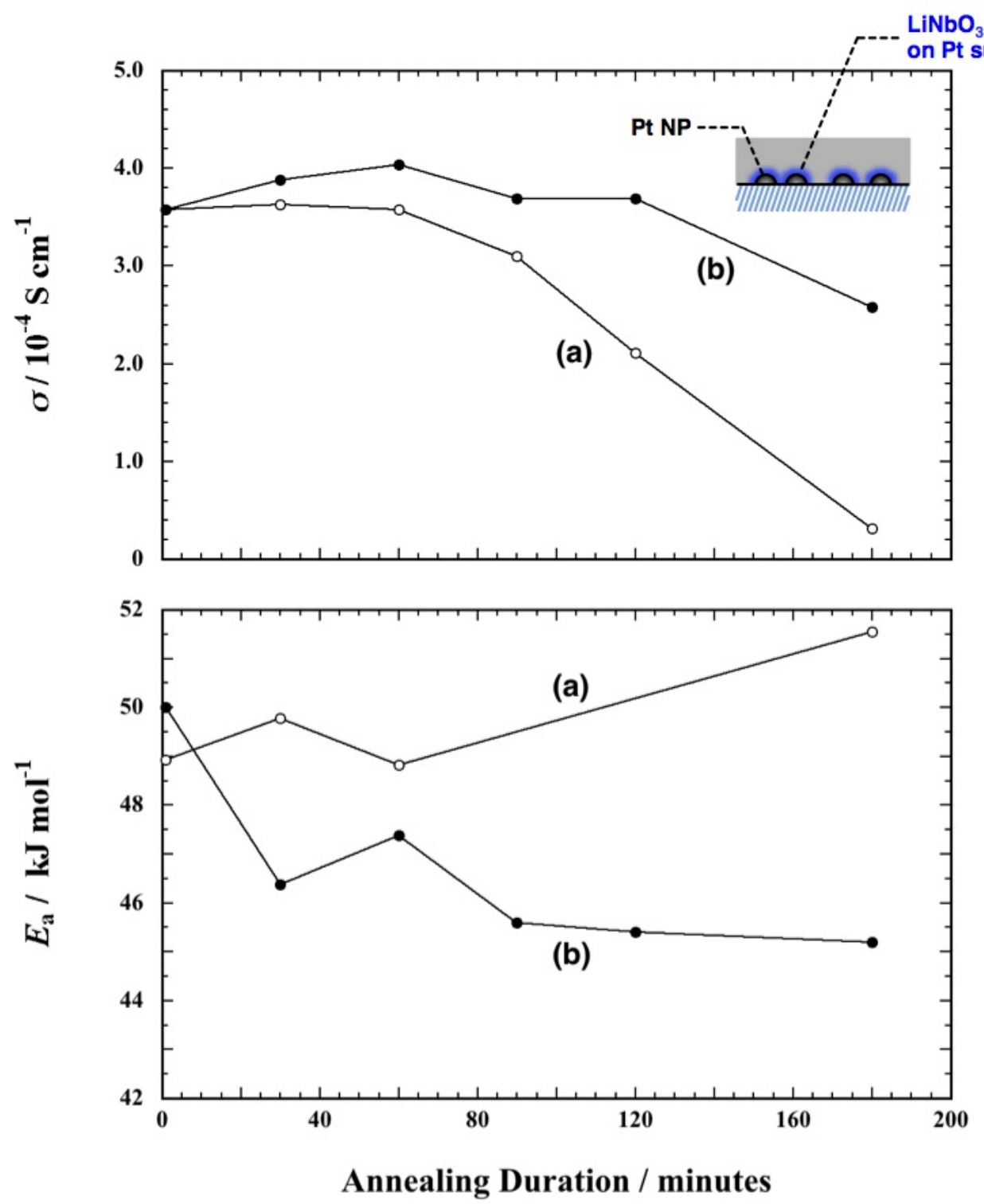

Figure 9. $\sigma\left(200{ }^{\circ} \mathrm{C}\right)$ and $E_{\mathrm{a}}$ of samples as function of the annealing duration (a) without and (b) with Pt NPs on substrates. $T_{\mathrm{a}}=425{ }^{\circ} \mathrm{C} . \mathrm{LiNbO}_{3}$ crystals nucleate on Pt-NP surfaces. Fast $\mathrm{Li}^{+}$conduction occurs through the regions in the vicinity of the amorphous/crystal interfaces in a Li-Nb-O film in (b). 